\title{
La reelección y el espejismo de la rendición de cuentas en México
}

\section{The re-election and the illusion of accountability in Mexico}

\author{
Rodrigo Edmundo Galán Martínez
}

Tribunal Electoral del Poder Judicial de la Federación rodrigo.galanmtz1@gmail.com

Recibido:06/06/18 | Aceptado: 26/11/18

RESUMEN: Se analiza la viabilidad de la reelección consecutiva de legisladores e integrantes de los ayuntamientos, como mecanismo de rendición de cuentas a cargo de la ciudadanía. Asimismo, se explica que la regulación de la reelección en la Constitución y la reciente interpretación de los Tribunales propician que se traslade el control de los ciudadanos sobre los representantes populares a los partidos políticos, debido a que éstos decidirán quienes serán nuevamente postulados. Como se evidencia en esta investigación documento, esto es contrario a la finalidad teórica de la reelección y a la de la propia reforma, la cual consiste en acercar más a los gobernantes con la ciudadanía para que sus demandas sean tomadas en cuenta y por el riesgo de no ser reelectos. Por último, se concluye que, mientras no se garantice la postulación de los representantes para su reelección, difícilmente esta figura será un mecanismo de rendición de cuentas.

PALABRAS CLAVE: democracia, partidos políticos, control ciudadano, disciplina partidista.

\begin{abstract}
The intention of this article is to analyze the viability of the consecutive reelection of legislators and members of the municipalities, as a mechanism of accountability in charge of the citizenship. In it, it is explained that the regulation of re-election in the Constitution and the recent interpretation of the Tribunals have transferred the control of citizens over popular representatives to political parties, because they will decide who will be nominated again. This document tries to show that this is contrary to the theoretical purpose of re-election, which consists of bringing the rulers closer to the citizens so that their demands are taken into account and because of the risk of not being reelected. Finally, it is concluded that, as long as the nomination of the representatives for their re-election is not guaranteed, this figure will hardly be a mechanism for accountability.
\end{abstract}

KEYWORDS: democracy, political parties, citizen control, party discipline. 


\section{SUMARIO}

I. Introducción. II. Democracia y rendición de cuentas. III. La rendición de cuentas electoral (reelección). III.1. (Des)vinculación de ciudadanos. III.2. Ausencia de justificaciones. IV. La reelección en México. IV.1. La finalidad de la reforma. IV.2. El control de los partidos políticos. IV.3. La consolidación del control partidista. V. Conclusiones. Bibliografía.

\section{Introducción}

Desde 2014, la Constitución mexicana prevé la posibilidad de que los titulares de diversos cargos de elección popular se reelijan de manera consecutiva (legisladores federales y locales e integrantes de los ayuntamientos). De hecho, en los procesos electorales locales y federal de 2018, será la primera oportunidad para que se aplique la reelección en algunos de esos puestos.

En la teoría, la reelección es considerada como un mecanismo de rendición de cuentas cuyas finalidades son esencialmente dos: 1) que se reduzca la distancia entre gobernantes y gobernados, de modo que se tomen en cuenta las necesidades y demandas de la ciudadanía, con el fin de que los representantes sean ratificados mediante el voto, y 2) que los ciudadanos cuenten con un mecanismo de control sobre los representantes, para premiar con la reelección a quienes califiquen como buenos gobernantes o, en su caso, preferir a otra opción política. Cabe aclarar que en el proceso de reforma constitucional mediante el cual se introdujo la reelección consecutiva en México, también se reconoció que tiene esas finalidades.

Pese a ello, el producto de la reforma ha sido que la reelección, como mecanismo de rendición de cuentas, esté supeditado, casi enteramente, a la decisión de los partidos políticos de postular nuevamente a los representantes populares. La redacción del texto constitucional ha llevado a que, recientemente, los Tribunales interpreten que los representantes electos carecen del derecho a postularse nuevamente para su posible reelección, sino que es necesario someterse a la decisión partidista, la cual, por estrategia política, puede elegir a otro candidato. 
Si se considera que la gran mayoría de candidatos llegan a los cargos de elección popular a través de los partidos políticos, y que quienes llegan a ser representantes populares por esa vía, no pueden hacerlo como candidatos independientes, se puede prever que existen los incentivos suficientes para que los representantes populares respondan a los intereses de los partidos políticos, y sólo sin son nuevamente postulados, puede llevarse a cabo la rendición de cuentas electoral ante la ciudadanía.

Pues bien, explicamos cómo es que la reelección, difícilmente, será un mecanismo de rendición de cuentas a la ciudadanía, mientras ésta dependa de la voluntad de los partidos políticos de postular nuevamente a los representantes populares. Para ello, primero explicaré cómo se conforma la reelección como mecanismo de rendición de cuentas al interior de un Estado democrático, y con base en ello, la forma en que se ha implementado su regulación en México.

\section{Democracia y rendición de cuentas}

Para que un Estado sea considerado democrático es necesario que en su interior se establezcan redes de responsabilidad y rendición de cuentas, de modo que todos los agentes públicos estén sujetos a controles apropiados y legalmente establecidos sobre sus actos, porque esto permite que nadie se asuma como legibus solutus (O’Donell, 2001, p. 24).

Si bien es cierto que la democracia representativa se sostiene en la idea de independencia de los representantes respecto de sus votantes, esta separación no debe tener por resultado gobiernos irresponsables o totalmente deslindados de las necesidades y demandas de los ciudadanos (Peruzzotti, 2010, p. 248).

De hecho, debido a esa separación se hace necesaria la implementación de mecanismos institucionales que aseguren que esa distancia no producirá gobiernos cuyas decisiones sean disímiles a las necesidades de la ciudadanía (Peruzzotti, 2010, p. 250), es decir, irresponsables. Al respecto, Dahl sostiene que un gobierno democrático se caracteriza fundamentalmente por su continua 
aptitud para responder a las preferencias de los ciudadanos (1997, p. 13).

Justamente, una de las finalidades de los mecanismos de rendición de cuentas (como la reelección) es que los representantes tomen en cuenta las necesidades o visiones de los ciudadanos. Asimismo, que sean los ciudadanos quienes cuenten con mecanismos para premiar o sancionar a los buenos o malos gobernantes, según sea el caso.

Rendir cuentas constituye la obligación de explicar a alguien el estado que guardan ciertos asuntos. Este concepto hace referencia a la capacidad de asegurar que los funcionarios públicos respondan por sus conductas, estén obligados a justificar e informar sus decisiones, y a que, eventualmente, puedan ser castigados por ellas, en caso de que sea necesario (Peruzzotti y Smulowitz, 2002, p. 25).

El concepto de rendición de cuentas incluye distintos niveles: 1) es la obligación de los políticos y funcionarios de informar de sus decisiones y de justificarlas públicamente, y 2) es la posibilidad de sancionar a los políticos y funcionarios cuando violenten sus deberes públicos (Schedler, 2008, p. 12). A partir de esto, se puede advertir que la rendición de cuentas es un mecanismo amplio de control del poder que contiene tres elementos característicos: la información, la justificación y la sanción.

De tal modo, los mecanismos de rendición de cuentas son útiles para asegurar que los representantes respondan de sus acciones. Se trata de una forma de prevenir y corregir los abusos de poder al obligar a los gobernantes a abrirse a la vista pública, a explicar y justificar sus actos, y a ser susceptibles de una sanción (López y Merino, 2009, p. 7).

La noción de rendición de cuentas se vincula con la idea de que un buen gobierno debe someterse a un sinfín de controles para asegurar el manejo responsable de los asuntos públicos (Peruzzotti, 2010,p. 250), Por eso, es necesario obligar a los representantes a informar sobre lo que hacen (answerability), y constituir medidas de sanción (enforcement), pues sólo al institucionalizar una 
estructura de rendición de cuentas puede obligarse a los representantes a hacerse responsables de sus actos (Olvera e Insunza, 2008, p. 341).

Ahora bien, los distintos tipos de rendición de cuentas tienen que ver con el tipo de responsabilidad exigida a los representantes. Existe una responsabilidad legal cuando se trate de asegurar que las acciones de los funcionarios públicos deben mantenerse dentro del marco constitucional y legal. La otra se denomina responsabilidad política, conforme a la cual, le corresponde a los ciudadanos juzgar sobre el desempeño de los representantes, de forma que se enfoca en la confianza de los ciudadanos sobre los elegidos, y funciona cuando existe la posibilidad de verificar las fallas de los políticos y sancionarlos (Peruzzotti, 2010, p. 248).

Esto evidencia la necesidad de que existan titulares capaces de exigir su cumplimiento, por lo que se coloca a los servidores públicos en un estado de obligación de responder sobre sus acciones u omisiones. Lo trascendente de esto es que los ciudadanos deben ser el centro de preocupación de la política, pues se trata de la razón de ser del poder público (Galán, 2010, p. 902).

Mediante los mecanismos de rendición de cuentas se pueden supervisar el funcionamiento y comportamiento de los representantes de forma que se pueden denunciar los casos de transgresión a la ley, de corrupción, o lograr que quienes designen a un funcionario juzguen su gestión. Es decir, los mecanismos de rendición de cuentas buscan que los representantes actúen responsablemente y teniendo en cuenta los intereses de los representados (Peruzzotti, 2010, p. 246).

Las diversas formas de exigir cuentas son necesarias para construir un verdadero control y responsabilidad de los representantes, pues protegen el derecho a una buena representación, dichas formas son: la horizontal y la vertical (electoral).

Mientras que en la rendición de cuentas horizontal se ejerce el control de los actos ilícitos de los representantes al imponerse sanciones de tipo legal a través de entes del propio estado, de modo que se busca que los representantes 
cumplan con los límites legales y constitucionales (O’Donell, 2002, p. 102), la rendición de cuentas vertical (electoral) contempla la posibilidad de controlar y responsabilizar políticamente a los gobernantes, pues consiste premiarlos o castigarlos mediante la reelección. Así, los políticos que no tengan un buen desempeño son castigados cuando no se les renueva la confianza (O’Donell, 1997, p. 24).

Como se ve, la rendición de cuentas horizontal se inclina sobre la responsabilidad jurídica de los servidores públicos, mientras que la rendición de cuentas vertical, en su vertiente electoral, busca responsabilizar políticamente a los funcionarios, y en su caso, sancionarlos con su remoción del cargo por medio de las elecciones. Aunque, el voto también ha sido concebido como un incentivo para obligar al gobierno a ajustarse a la ley cuando la reelección es una posibilidad (Ugalde, 2002, p. 32).

\section{La rendición de cuentas electoral (reelección)}

La rendición de cuentas electoral, como mecanismo de control, supone la existencia de dos sujetos: los electores y los representantes. Debido a que los representantes tienen a su cargo las decisiones de los asuntos públicos y éstas vinculan a los ciudadanos, deben ser responsables de ellas.

En ese escenario, los representantes deben estar en posición de ser juzgados y, a su vez, los electores deben estar en aptitud de calificar su actuar y responsabilizarlos por su gestión. De tal modo, mediante el voto se puede reflexionar sobre la forma en que los representantes han llevado la dirección de los asuntos públicos y, en su caso, recompensar con la reelección a aquellos que hayan tenido una buena gestión, o bien, sancionarlos con la ausencia de voto a aquellos que sean juzgados de manera negativa.

En el proceso de rendición de cuentas, las elecciones sirven para hacer responsables a los representantes de los resultados de sus acciones pasadas. Mediante esta evaluación de los votantes, los representantes son inducidos a 
escoger las políticas que, a su juicio, son positivas para los ciudadanos. (Manin, Przeworski y Stokes, 2002, p. 25). De este modo, las elecciones funcionan como un mecanismo condicionante a la actuación de los representantes, porque, en teoría, con la reelección son persuadidos a ser sensibles a las necesidades y demandas de los electores, si desean ser reelectos (Martínez, 2004, p. 668).

En palabras de O’Donell (1997, p. 150) la rendición de cuentas electoral se da en las elecciones razonablemente limpias y libres, en las que los ciudadanos pueden castigar o recompensar a los representantes votando a favor o en contra de ellos, o de los candidatos que ellos apoyan, en la próxima elección.

En esas condiciones, la rendición de cuentas electoral ocurre cuando si: 1) los votantes deciden renovar la confianza en los representantes si estos obran de acuerdo a los mejores intereses, 2) cuando el gobierno adopta las medidas necesarias para su reelección, o 3) cuando son castigados por los electores, al no volver a votar por ellos.

En ese sentido, la rendición de cuentas vertical en su vertiente electoral se da a través de la reelección, pues permite castigar a los malos representantes o en su caso renovarles la confianza, por lo que las elecciones son indispensables para seleccionar a quienes puedan desempeñar una función de mejor manera.

La democracia puede generar representación cuando los gobiernos rinden cuentas de su gestión, es decir, cuando los ciudadanos pueden castigarlos o recompensarlos con el voto en las elecciones, debido a que pueden perder elecciones. Esas recompensas o castigos son producto de una evaluación retrospectiva que se refleja al momento de votar (Maravall, 2006, p. 10).

\section{III.1. (Des)vinculación de ciudadanos}

Esta vertiente de la rendición de cuentas tiene que ver también con la posibilidad de que los ciudadanos puedan incidir en las decisiones de los representantes, por lo tanto, también cumplen un papel central de asegurar que los gobiernos 
respondan a los intereses de los representados (Peruzzotti, 2010, p. 250). Por eso, mediante la reelección es posible crear un vínculo entre representantes y representados que vaya más allá de las campañas electorales y el momento en que se vota (Tovar, 2010, p. 195), pues con ello se persigue que el interés de los gobernantes hacia los electores se mantenga durante todo su encargo, con el incentivo de ser reelectos. La reelección crea un incentivo fuerte para que los gobernantes actúen en beneficio de la ciudadanía ante la posibilidad de ser electos nuevamente en el cargo (Ugalde, 2002, p. 20).

De este modo, mediante la reelección, la delegación de poder de la ciudadanía a los gobernantes no es absoluta, porque los electores no pierden enteramente su capacidad de control sobre ellos, debido a que mantienen la posibilidad de responsabilizarlos y sancionarlo al elegir una alternativa política distinta a ellos (Avendaño, 2008, p. 103).

Por el contrario, cuando no existe reelección, los representantes tienen incentivos para actuar según sus intereses, porque la vinculación con los electores en realidad termina al momento en que resultan triunfadores en el proceso electoral, por otro lado. Sin embargo, este vacío, se torna en beneficio de los partidos políticos, pues es a éstos a quienes los políticos electos rinden cuentas, debido a que de ellos depende la continuidad de su carrera política (Tovar, 2010, p. 196 y Reveles, 2011, p. 16), lo cual genera que la agenda política de los partidos sea la que impere y no la de los ciudadanos.

Por ejemplo, en el caso de los integrantes del Congreso, la ausencia de reelección, ha generado que los mecanismos de control parlamentario sean ejercidos por las dirigencias partidistas y no por los electores. En ese escenario, lo que existe es una representación de partido, porque al no existir incentivos para considerar las inquietudes ciudadanas, los partidos políticos son los que ejercen el mandato sobre el legislador, a través de incentivos como premiar o castigar su lealtad y disciplina parlamentaria (Casar, Marván y Puente, 2010, p. 4).

Otro modo de verlo es que, cuando no hay reelección, los representantes electos tienen intereses vinculantes con quienes los ayudaron a llegar al cargo 
(patrocinadores), por lo que desvían su mandato del interés general, de ahí que quienes exigen cuentas pueden ser los empresarios, grupos políticos u otros grupos de interés (Estrada, 2012, p. 49).

\section{III.2. Ausencia de justificaciones}

Por otro lado, la ausencia de reelección no contribuye a la rendición de cuentas, porque impide la consolidación de instituciones que generen la obligación de los gobernantes de explicar y justificar sus acciones ante la ciudadanía (Cejudo y Ríos, 2010, p. 108). Al no ser políticamente responsables los gobernantes, ni siquiera tienen la obligación de informar o justificar sus decisiones (Casar, Marván y Puente, 2010, p. 53).

Un ejemplo evidente de la falta de vinculación entre representantes y representados, es la ausencia de explicaciones respecto de las promesas de campaña. Antes de que los representantes obtengan un cargo, generalmente, es necesario que sigan un proceso electoral en el que teóricamente deben ofrecer al electorado distintas propuestas para que este decida por quién votar. Los partidos y candidatos formulan propuestas y explican cómo es que esas políticas afectarían el bienestar de los ciudadanos; estos deciden cuáles de esas propuestas quieren que sean implementadas y a qué políticos encargar esa implementación (Luna, 2007, p. 394).

Bajo este esquema, las campañas electorales son una forma de controlar la gestión de los representantes, porque cuando los políticos se someten a la reelección, los ciudadanos pueden vigilar el cumplimiento de las promesas electorales. Los ciudadanos utilizan expectativas racionales al tratar de seleccionar al mejor candidato y consideran que el futuro forma parte del propósito de las elecciones (Maravall, 2006, p. 39). Posteriormente, las promesas de campaña pueden servir para vincular a los representantes, porque en una nueva elección los electores pueden juzgar los resultados de las promesas cumplidas o su incumplimiento. 
Ahora bien, los representantes, al ser independientes de sus electores, no están obligados a implementar las políticas preferidas de los votantes (Przeworski, 1997, p. 15; Manin,1998, p. 290), por lo que su cumplimiento queda a su entera decisión, pues una vez que los representantes son electos pueden determinar libremente no atender a sus promesas de campaña sin justificación, máxime si en los sistemas representativos no se permite la reelección.

De esta forma, los electores quedan a expensas de los representantes, pues seguir o no las propuestas está bajo su entera discreción, por lo que pueden incluso tomar una postura distinta y contraria a la que defendieron durante la campaña electoral (Galán, 2015, p.302). En esas condiciones, el mandato se traduce en una plataforma del partido y en promesas que, una vez que el representante toma el cargo, incumple, sin que los ciudadanos puedan actuar, y sin que exista ni siquiera la obligación de justificar sus decisiones (Estrada, 2012, p. 49).

\section{La reelección en México}

\section{IV.1. La finalidad de la reforma}

En México, existía la prohibición constitucional para la reelección de diputados federales y locales, senadores e integrantes de los ayuntamientos desde 1933. El principal argumento de esa reforma era evitar el continuismo y formación de cotos de poder (Ugalde y Rivera, 2014, p. 192).

Después de múltiples intentos por restaurar la reelección consecutiva ${ }^{1}$,

\footnotetext{
1 Barquín, M. (2004, p. 94). señala que en 1964, el Partido Popular Socialista propuso que los diputados federales pudieran ser reelegidos el número de veces que los partidos políticos lo decidiera cuando obtuvieran el número de votos necesarios, ya fuese por mayoría o como diputados de partido. Por otro lado, Tovar (2010, p. 89), señala que en 2005 se dio un nuevo intento para introducir la reelección inmediata, a través de una iniciativa impulsada por el titular del Ejecutivo, que contó con el apoyo del PRI, PAN, y PRD en la Cámara de Diputados, la cual se aprobó en tal Cámara pero a pesar de esto y de que fue dictaminada favorablemente por las comisiones del Senado, no fue aprobada por los integrantes de la Cámara Alta. Asimismo, en Ugalde y Rivera, G. (2014, p. 202) narran que en 2011 el senado aprobó una iniciativa que proponía la reelección legislativa, sin embargo, fue rechazada por la Cámara de Diputados. Cortez (2011, p. 1322) describe las distintas etapas en las que se presentaron solicitudes de reforma para permitir la reelección de legisladores.
} 
hasta 2014 se publicó la reforma constitucional que suprimió la prohibición de que los diputados federales y locales, senadores e integrantes de los ayuntamientos se reeligieran continuamente (SEGOB, 2014).

Con esta reforma, en el artículo 59 de la Constitución Federal, se estableció que los senadores pueden ser electos hasta por 2 periodos consecutivos, mientras que los diputados federales podrán serlo por 4. Por su parte, en el artículo 116, fracción II de la misma norma constitucional, se dispuso que los diputados locales pueden ser electos de manera consecutiva hasta por 4 periodos. Mientras que en el artículo 115 constitucional solo se autorizó la reelección de ayuntamientos sólo por un periodo adicional, siempre que su mandato no dure más de 3 años.

En las mismas disposiciones constitucionales se estableció la reelección sólo podrá ser por el mismo partido o por cualquiera de los integrantes de la coalición que hayan postulado a los candidatos en la primer elección, excepto cuando hayan renunciado o perdido su militancia antes de la mitad de su mandato.

Para entender las razones que llevaron a los legisladores a redactar las disposiciones constitucionales relacionadas con la reelección, resulta conveniente exponer algunos momentos del proceso de reforma correspondiente.

Cabe señalar que la cámara de origen fue la de Senadores y a sus respectivas comisiones le correspondió analizar 36 iniciativas para reformar distintas disposiciones constitucionales sobre diversos temas que derivaron en una reforma político-electoral que no sólo incluyó a la reelección. En concreto, respecto a la reelección de legisladores federales y estatales, así como de integrantes de ayuntamientos, en el Dictamen ${ }^{2}$ correspondiente se analizaron 3 iniciativas (Cámara de Senadores, 2013).

Dentro de ellas, destaca la de la senadora Mariana Gómez del Campo,

2 Cámara de Senadores (2 de marzo de 2013). Dictamen de las Comisiones Unidas de Puntos Constitucionales; de Gobernación; de Reforma del Estado; de estudios Legislativos, Primera y de Estudios Legislativos Segunda, en relación con las iniciativas con proyecto de decreto por el que se reforman y adicionan diversos artículos de la Constitución Política de los Estados Unidos Mexicanos en Materia Político-Electoral. Recuperado de http:// www.diputados.gob.mx/LeyesBiblio/proceso/docleg/62/216_DOF_10feb14.pdf 
quien sostenía que la reelección podría funcionar como un incentivo para los ciudadanos, quienes tendrían el poder de premiar o castigar al representante. En la misma iniciativa se destacó que sin la reelección los legisladores no tenían incentivos para rendir cuentas a los ciudadanos, sino a los partidos políticos y sus cúpulas para garantizar su carrera política (Cámara de Senadores, 2013). Cabe señalar que, en ella, también se proponía que quienes desearan ser reelectos debían someterse a un proceso interno al interior del partido que los postuló para el cargo, para que su militancia decidiera si eran idóneos para ser nuevamente postulados o no.

La senadora Gabriela Cuevas Barrón también presentó una iniciativa en materia de reelección en la que incluyó a los legisladores federales y a los ayuntamientos. En la exposición de motivos de la propuesta se señaló que la reelección de legisladores tenía la finalidad de crear un mecanismo de rendición de cuentas en favor de los ciudadanos y la profesionalización de los funcionarios. En cuanto a la elección consecutiva de ayuntamientos se argumentó la existencia de evidencia de que existe menos riesgo de corrupción por parte de los funcionarios que tienen la posibilidad de reelegirse respecto a los que no y con el fin de mejorar la gestión de gobierno (Cámara de Senadores, 2013).

El grupo parlamentario de los senadores del Partido Acción Nacional también presentaron una iniciativa para permitir la reelección de los integrantes de los ayuntamientos pero proponían que fueran las entidades federativas quienes definieran las bases para un periodo consecutivo (Cámara de Senadores, 2013).

Debe destacarse que en el Dictamen referido, se concluyó que con la reelección de legisladores se buscaba: 1) Un vínculo más estrecho con los electores y rendición de cuentas, porque mediante el voto se les puede ratificar en el cargo; 2) La profesionalización de la carrera de los legisladores, y 3) El fortalecimiento del trabajo legislativo mediante la continuidad de los legisladores. Respecto a la reelección de integrantes de los ayuntamientos no se dieron más razones que la necesidad de ampliar los cauces de participación y fortalecer el concepto constitucional de municipio libre. 
Durante la discusión del Dictamen ante el Pleno, el senador Raúl Gracia Guzmán argumentó que con la reelección se buscaba cambiar el vínculo de dependencia de los representantes con los partidos y que con ella se otorgaría más poder al ciudadano (Cámara de Senadores, 2013).

Por su parte, el senador Javier Corral Jurado justificó que la reelección se diera únicamente mediante la postulación del partido (o integrantes de la coalición) que llevó al cargo al funcionario electo para evitar el trasfuguismo (Cámara de Senadores, 2013).

Una vez que el Dictamen fue discutido y aprobado por la Cámara de Senadores, se remitió a la Cámara de Diputados. En materia de reelección, la Cámara revisora modificó la minuta al establecer que podrían ser objeto de reelección los legisladores federales que fueran electos a partir de 2018, pues la propuesta de la Cámara de Senadores era que los diputados federales surgidos del proceso electoral de 2015 pudieran ser reelectos (Cámara de Senadores, 2013). La Cámara de Senadores, al pronunciarse sobre las modificaciones de la Cámara de Diputados, coincidió en que la reelección de legisladores federales iniciara con quienes fueran electos en 2018.

Una vez que la Comisión Permanente del Congreso de la Unión recibió la noticia de que 18 Congresos estatales aprobaron la reforma, realizó la declaratoria correspondiente y la remisión al Poder Ejecutivo para realizar el trámite correspondiente (Cámara de Senadores, 2013).

Ahora bien, de lo anterior puede advertirse que la finalidad de reforma constitucional en materia de reelección fue fortalecer el vínculo de representantes con los ciudadanos y la rendición de cuentas, las iniciativas expuestas y el Dictamen de las Comisiones de la Cámara de Senadores evidencia, al menos en el papel, que la reforma constitucional buscaba esa meta.

De hecho, en la acción de inconstitucionalidad 76/2016, la Suprema Corte de Justicia de la Nación sostuvo que el objetivo pretendido con la reelección es conseguir una relación más estrecha entre el electorado y los funcionarios electos mediante el sufragio, propiciar una participación democrática más activa y una 
mayor rendición de cuentas ante los ciudadanos, con lo cual se muestra cuál es la finalidad de la elección consecutiva de tales cargos.

\section{IV.2. El control de los partidos políticos}

Como ya vimos, en la reforma constitucional se estableció que para que pueda haber reelección de legisladores e integrantes de ayuntamientos es necesario: 1) Que la postulación sea por el mismo partido o por los que integraron coalición que lo postuló al cargo, y 2) Salvo que hayan renunciado o perdido su militancia antes de la mitad del mandato ${ }^{3}$.

En el Dictamen de las Comisiones del Senado se explica que el legislador que pretenda reelegirse, tiene que hacerlo por la misma vía mediante la que obtuvo el cargo. Cuando hayan sido electos en candidaturas de partidos políticos no pueden hacerlo a través de una candidatura independiente. Por su parte, los candidatos independientes no pueden reelegirse utilizando como vía a los partidos políticos (Cámara de Senadores, 2013). Lo mismo se previó para los integrantes de ayuntamientos que deseen reelegirse.

Además, en la Constitución establece que la postulación por el partido o integrantes de la coalición podrá darse salvo que los funcionarios electos hayan renunciado o perdido la militancia.

Advierto que existe una contradicción entre las finalidades teóricas de la reelección con el texto constitucional aprobado. Si lo que se buscaba era alcanzar un acercamiento entre los representantes populares y la ciudadanía, esta reforma otorgó incentivos adversos a ese fin. Al exigir que los legisladores e integrantes de ayuntamientos se postulen por los mismos partidos políticos con los que llegaron al cargo, se le otorga a estos entes el control de la gestión de los políticos.

El incentivo que se genera es que, al ser la única vía posible, los representantes deben procurar no ser expulsados del partido que los postuló, o

3 Véanse artículos 59, 115, fracción I, y 116 fracción II, de la Constitución Política de los Estados Unidos Mexicanos. 
bien, congraciarse con los otros partidos que fueron integrantes de la coalición, pues de lo contrario, pierden su derecho a ser reelectos. A la inversa, los líderes partidistas tienen incentivos para controlar las decisiones de quienes ocupan estos cargos, pues si son desobedecidos cuentan con los mecanismos al interior del partido para imponer la disciplina partidista y expulsarlos.

Benito Nacif (1997, p. 123) ha explicado que la prohibición de la reelección consecutiva en México para los legisladores y gobiernos municipales provocó que quienes ocuparan esos cargos y tuvieran el deseo de desarrollar una carrera política, aspiraran pasar de un cargo a otro para sobrevivir en la política, por lo cual, los políticos empezaron a depender enteramente de los dirigentes nacionales de los partidos. Por ello, la no reelección generó un régimen de rotación de cargos, cuya promoción dependía de la dirigencia del partido. Nacif explica que los actores relevantes en la rotación de cargos eran la organización externa del partido y el poder ejecutivo, quien sancionaba o premiaba el comportamiento de los políticos en el Congreso (1997, p.143).

Si bien es cierto que con la reforma constitucional de 2014 se terminó con el periodo que impedía la reelección de legisladores y gobiernos municipales, las cúpulas partidistas mantienen el poder de designación y disciplina sobre los políticos, al establecer que quienes deseen ser reelectos en esos cargos deben contender por el mismo partido o integrante de la coalición que los postuló (Casar, 2014, p. 336)

La forma como se aprobó la reelección de legisladores e integrantes de los ayuntamientos en México permite a los partidos mantener el control sobre los representantes populares, pues ellos pueden decidir quién tiene derecho a reelegirse y quién no. Esto si se considera que son muy pocos los casos en los que los candidatos independientes llegan a ocupar los cargos de elección popular.

Lo anterior, evidentemente, es contrario a las finalidades de la reelección, pues en vez de fortalecer los incentivos para que los políticos se preocupen por las demandas de sus electores y busquen dar buenos resultados para ser reelectos, se robusteció el control de los partidos políticos, al prever que sean éstos quienes 
decidan quienes serán sometidos a reelección. Los incentivos se dirigen a que sean los partidos quienes decidan qué gobernantes deben rendir cuentas y cuáles no ante la ciudadanía, al ser ellos quienes cuentan con los mecanismos para decidir si postulan a los representantes o no con miras a la reelección. El riesgo es fomentar la partidocracia o el estado de partidos, conforme al cual, los partidos políticos concentran el poder en detrimento de la democracia y son exclusivamente las dirigencias de los partidos los que deciden las candidaturas (De Cabo, 2013, p. 110), en perjuicio de la participación ciudadana.

Para Béjar (2003, p. 223) cuando los partidos políticos se convierten en intermediarios políticos, no existe independencia de los representantes debido a la disciplina que imponen dichos entes, por eso, en las legislaturas el interés ciudadano no se encuentra en el primer plano, sino la imposición de los líderes partidistas (Béjar, 2003, p. 224). La forma como se aprobó la reelección en México incentiva a que los partidos políticos se conviertan en intermediarios de la reelección, pues quienes fueron originalmente electos por esa vía deben ser reelectos de la misma forma.

Cabe señalar que, el electorado es más débil frente a los agentes políticos, y la posibilidad de que los representantes hagan caso omiso o se desvíen de su mandato es mayor que en otras democracias que sí cuentan con una conexión más estrecha entre gobernados y gobernantes (Ugalde, 2002, p. 36).

En principio, pareciera ser que sólo habrá rendición de cuentas cuando: a) los representantes populares sean postulados por el mismo partido que lo hizo para obtener el cargo; b) cuando alguno de los partidos que conformaron la coalición por la que llegó al cargo lo postule; c) cuando los representantes populares sean expulsados o renuncian al partido que los postuló, pueden ser propuestos como candidatos por los integrantes de la coalición, y d) cuando hayan llegado al cargo por una candidatura independiente y nuevamente se postulen al puesto.

De este modo, no se tutela a la reelección como una forma efectiva para que exista rendición de cuentas electoral. Para ello, sería necesario que quien ocupe los cargos, tuviera garantizado su derecho a postularse nuevamente al mismo cargo 
para recibir el juicio de la ciudadanía. Con ello, se tutelaría en gran medida el ciclo de la rendición de cuentas electoral, por el contrario, de la forma como se reguló la reelección, la rendición de cuentas está a disposición de los partidos políticos.

\section{IV.3. La consolidación del control partidista}

La viabilidad de que la reelección se constituya como un medio efectivo de rendición de cuentas es aún más estrecha, porque en el ámbito judicial se ha interpretado que el derecho de los representantes populares a postularse para una reelección es sólo una posibilidad, cuya decisión está a cargo de los partidos políticos. En ese sentido se pronunció el Tribunal Electoral del Poder Judicial de la Federación en la sentencia del juicio SUP-JDC-35/2018 y acumulado (TEPJF, 2018).

Este asunto se originó por la impugnación promovida en contra de los criterios para garantizar la paridad de género en las planillas que el Partido Acción Nacional (PAN) postularía para los ayuntamientos del Estado de México, en la que se reservaron diversos distritos electorales y candidaturas a presidencias municipales para que fueran ocupadas por mujeres. Los demandantes consideraron, entre otras cuestiones, que quienes tenían el cargo de presidentes municipales tienen el derecho a postularse para ser objeto de reelección.

Al respecto, el Tribunal Electoral sostuvo que, de acuerdo al marco constitucional: a) el triunfo en una elección no produce que, automática y obligatoriamente, deban ser postulados por los partidos políticos, es decir, no hay un derecho adquirido de los representantes populares; b) ser postulados nuevamente es una posibilidad, siempre que los representantes populares cumplan con procedimientos y requisitos establecidos por cada partido político; c) los partidos tienen derecho a definir si la postulación es oportuna en términos de su normativa interna; d) en el nuevo procedimiento de definición de candidaturas confluyen aspectos como la autodeterminación de los partidos políticos, la estrategia política, los resultados del ejercicio de gobierno, el contexto histórico y social, el resto de derechos fundamentales den juego (TEPJF, 2018). 
Como se advierte, la interpretación del Tribunal Electoral, conforme al marco constitucional, es que los funcionarios electos (legisladores e integrantes del ayuntamiento) no tienen el derecho de postularse para su reelección por el sólo hecho de resultar ganadores de la elección previa. El derecho a reelegirse se adquiere después de que cumplen los requisitos establecidos al interior de los partidos políticos para postular las candidaturas en una nueva elección.

En este contexto, es necesario tener en cuenta que en la accountability electoral -dentro de la cual forma parte la reelección- existe el principio de maximización de la rendición de cuentas directa de los representantes de elección popular a los electores, y cuando se introducen intermediarios en esa relación se debilita el incentivo electoral para que quienes aspiren a una reelección se mantengan vinculados a los votantes (Shugart y Mainwaring, 2002, p. 41).

Con la interpretación realizada por el Tribunal Electoral, los partidos políticos se convierten en intermediarios necesarios para que los funcionarios electos rindan cuentas electoralmente, pues primero deben ser seleccionados por la organización política para poder ser sometidos al electorado nuevamente.

En estas circunstancias, la reelección, como mecanismo de rendición de cuentas, está a expensas de la decisión de los partidos políticos, ya que éstos tienen los mecanismos de control respecto de la gestión de los representantes y, recíprocamente, éstos tienen los incentivos para seguir la agenda que dicten los partidos políticos.

Debe recordarse que, por disposición constitucional, los representantes cuyos cargos son susceptibles de ser reelectos, forzosamente deben postularse por la vía mediante la que fueron inicialmente electos -el partido al que pertenecen y los postuló o alguno de los integrantes de la coalición que los llevaron al cargo- y no pueden hacerlo por la vía independiente.

Adicionalmente, no basta con que los representantes se mantengan durante su gestión dentro del partido político que los postuló, pues como se expuso, es necesario que se sometan a su decisión para poder ser postulados. 
Esto debe ser valorado en el contexto en que la mayoría de los cargos de elección popular en el país son ocupados por candidatos postulados por partidos políticos (Macedo, 2017).

La necesidad de que la nueva postulación de los legisladores e integrantes de los ayuntamientos dependa de la decisión de los partidos políticos genera, nuevamente, el mismo incentivo que existía cuando se prohibía la reelección. Quienes busquen continuar con su carrera política mediante la reelección requieren la aprobación de los líderes partidistas, porque son estos quienes cuentan con la influencia decisiva para nombrar a los candidatos (Nacif, 2006, p.15).

Sobre todo, en el contexto mexicano, en el que históricamente, los partidos políticos han sido concebidos como coordinadores de un esquema de rotación de cargos, debido a la influencia con que cuentan sus dirigentes para postular candidatos (Nacif, 2006, p. 27)

Entonces, existen dos barreras que los representantes populares deben superar para poder ser postulados nuevamente y someterse a reelección. Primero, no ser expulsados del partido político. Segundo, aun cuando se mantengan en el partido político en el lapso que dure su función, deben someterse al procedimiento interno y a sus decisiones. Incluso, aun cuando decidieran competir bajo las siglas de un partido integrante de la coalición con la que llegaron al cargo, también sería necesario someterse a las decisiones internas.

Es decir, ante el escenario en el que casi no hay representantes populares que lleguen por la vía independiente, la rendición de cuentas electoral depende casi, exclusivamente, de la voluntad de los partidos políticos. En esas condiciones, es probable que el estado de las cosas se mantenga en el ámbito político mexicano, el cual ha sido criticado por existir poca consolidación ciudadana en detrimento de la democracia, porque las prácticas autoritarias son las que se han impuso en el control interno de los partidos políticos y son las redes políticas las que han establecido las condiciones de acceso al poder político (Tahar, 2012, p. 30). 
Es importante señalar que esto ha sido consecuencia de que se conciba a la reelección como un derecho individual de los representantes a postularse nuevamente, que debe ceder ante el derecho de autodeterminación de los partidos políticos. Sin embargo, al ser un mecanismo de rendición de cuentas, no sólo puede ser visto como el derecho individual de los políticos a ser votados nuevamente, sino como un derecho de la ciudadanía de juzgar la labor de los representantes en las urnas.

Es un derecho de los ciudadanos a premiar a los buenos representantes y a no renovar a los que considere que no lo son. Ugalde señala que debe existir un interés colectivo en beneficio de los votantes, con el fin de que existan mayores atribuciones y sanciones electorales para que esté constituido el ciclo de la rendición de cuentas (2002, p. 38).

En ese sentido, para que la reelección sea viable como un mecanismo de rendición de cuentas, es necesario que se garantice que los legisladores e integrantes de los ayuntamientos puedan contender en la siguiente elección, aun sin la venia del partido o partidos que los postularon.

\section{Conclusiones}

Las posibilidades de que la reelección sea un mecanismo de rendición de cuentas es reducido, porque la reforma constitucional que la implementó ha generado los incentivos para que los legisladores e integrantes de los ayuntamientos rindan cuentas a los partidos políticos, porque son éstos los que deciden quienes tienen el derecho a postularse nuevamente y quiénes no.

La posibilidad de someter a los representantes populares al juicio y sanción ciudadana se reducirá a aquellos casos en los que los partidos políticos elijan a esos políticos como candidatos al mismo cargo de manera consecutiva.

Para que este mecanismo de rendición de cuentas sea viable, es necesario que se garantice a los representantes postularse a la reelección con independencia de la decisión de los partidos políticos, pues sólo así se puede fomentar el vínculo

\section{DERECHO GLOBAL. ESTUDIOS SOBRE DERECHO Y JUSTICIA}


con la ciudadanía, de lo contrario, imperará la disciplina que imponen los partidos políticos.

No es posible que esto ocurra mediante la interpretación de los Tribunales electorales, porque el texto constitucional impide que los representantes contiendan por la vía independiente cuando hayan sido electos por medio de los partidos políticos. Por eso, se requiere una reforma que elimine esta prohibición.

Es un error considerar a la reelección como un derecho individual de los representantes a ser electos nuevamente. Es también un derecho de los ciudadanos de juzgar su gestión mediante el voto. Por tanto, cualquier reforma o interpretación de los tribunales debe advertir que la reelección protege el derecho de la ciudadanía de responsabilizar a los gobernantes.

En conclusión, la forma como se reguló la reelección genera un espejismo de la rendición de cuentas, porque en vez de acercar más a los representantes con los ciudadanos, se fortaleció el control que los partidos políticos ejercen sobre ellos.

\section{Bibliografía}

Avendaño, O. (2008). "De la autonomía del mandato a la rendición de cuentas. Un alcance conceptual a los mecanismos de representación democrática". Revista de Sociología (22), pp. 93-116.

Barceló, D. (2010). La responsabilidad política en el sistema presidencial mexicano. Un análisis conceptual. En J. Carpizo y C. Arriaga (coords.). Homenaje al Doctor Emilio O. Rabasa (pp. 23-60). México: UNAM.

Barquín, M. (2004). Comentario al artículo 59 constitucional. En Constitución Politica de los Estados Unidos Mexicanos comentada y concordada (84-98). México: Porrúa-UNAM.

Béjar, L. (2003). La reelección parlamentaria inmediata: un reto para la agenda política de México. Revista Mexicana de Ciencias Politicas 
y Sociales, 46 (187), pp. 203-227.

Cámara de Senadores (2 de marzo de 2013). Dictamen de las Comisiones Unidas de Puntos Constitucionales; de Gobernación; de Reforma del Estado; de estudios Legislativos, Primera y de Estudios Legislativos Segunda, en relación con las iniciativas con proyecto de decreto por el que se reforman y adicionan diversos articulos de la Constitución Política de los Estados Unidos Mexicanos en Materia Político-Electoral. Recuperado de http://www.diputados.gob.mx/ LeyesBiblio/proceso/docleg/62/216_DOF_10feb14.pdf

Casar, M., Marván, I. y Puente, K. (2010). La rendición de cuentas y el poder legislativo. México: CIDE.

Casar, M. (2014). La reforma política en México. Anuario Internacional CIDOB, (1), pp. 333-340.

Cejudo, G. y Ríos, A. (2010). La rendición de cuentas del gobierno municipal. En M. Merino, S. López y G. Cejudo (coords.), La estructura de la rendición de cuentas en México (pp. 87-114). México: UNAM.

Cortez, J. (2011). La propuesta de reelección inmediata de legisladores en la reforma del estado de 2010. Boletín Mexicano de Derecho Comparado, XLIV (132), pp. 1321-1333.

Dahl, R. (1997). La poliarquía. Madrid: Tecnos.

De Cabo. A. (2013). Representación y democracia como formas de legitimación y como formas de gobierno en el constitucionalismo. En A. Noguera (coord.), Crisis de la democracia y nuevas formas de participación (pp. 102-122). México: Tirant lo Blanch.

Estrada, J. (2012). La crisis de los partidos políticos como intermediarios de la representación: un obstáculo para la calidad de la democracia". Explanans, 1 (1), pp. 39-62.

Galán, M. (2010). Formas de estado de derecho y delimitación del derecho al buen gobierno. Arbor Ciencia, Politica y Cultura, ( 745), pp. 901-915.

Galán, R. (2015). El control ciudadano de los representantes y la rendición de cuentas. Revista de Derecho (43), pp. 293-321. 
Herdeggen, M. (2007). Estado de derecho, responsabilidad política y buena gobernabilidad. Estudios sociojurídicos, 9 (2), pp. 11-26.

López, S. y Merino, M. (2009). La rendición de cuentas en México: perspectivas y retos. México: Secretaría de la Función Pública.

Luna, J. (2007). Representación política en América Latina: el estado de la cuestión y una propuesta de agenda. Política y Gobierno, XIV (2), pp. 391-435.

Macedo, I. (22 de marzo de 2017). Candidatos independientes, otra opción a los partidos pero con poco éxito. Nación 321. Recuperado en http:// www.nacion321.com/elecciones/candidaturas-independientes-otraopcion-a-los-partidos-pero-con-poco-exito.

Manin, B. (1998). Los principios del gobierno representativo. Madrid: Alianza.

Manin, B., Przeworksi, A., y Stokes, S. (2002). Elecciones y representación. Zona Abierta, (101/102), pp. 19-46.

Maravall, J. (2006). La democracia y la supervivencia de los gobiernos. Revista Española de Ciencia Política, (15), pp. 4-45.

Martínez, M. (2004). La representación política y la calidad de la democracia. Revista Mexicana de Sociología, 66 (4), pp. 661-710.

Nacif, B. (1997). La rotación de cargos legislativos y la evolución del sistema de partidos en México. Política y Gobierno, IV (1), pp. 115145.

Nacif, B. (2007). Para entender las instituciones políticas del México democrático. México: CIDE.

O’Donell, G. (1997). Rendición de cuentas horizontal y nuevas poliarquías. Nueva Sociedad, (152), pp. 143-167.

O’Donell, G. (2001). La irrenunciabilidad del Estado de Derecho. Revista Instituciones y Desarrollo, (8-9), pp. 3-40.

O’Donell, G.(2002). Acerca de varias accountabilities y sus interrelaciones. En E. Peruzzotti (ed.), Controlando la política (pp. 87-102). Buenos Aires: Temas.

O’Donell, G. (2004). Accountability horizontal: la institucionalización legal de la desconfianza política. Revista Española de Ciencia 
Política, (11), pp. 11-31.

Olvera, A. e Insunza, E. (2008). Rendición de cuentas: los fundamentos teóricos de una práctica ciudadana. EnA.Ziccardi(ed.), Participación ciudadana y políticas sociales en el ámbito local (pp. 335-357). México: UNAM.

Peña, J. (1998). Sobre la responsabilidad política. Revista Internacional de Filosofia Politica, (11), pp. 127-148.

Peruzzotti, E. y Smulovitz, C. (2002). Accountability social: la otra cara de control. En E. Peruzzotti (ed.), Controlando la política (pp. 2385). Buenos Aires: Temas.

Peruzzotti, E. (2010). La política de accountability social en América Latina. En E. Insunza y A. Olvera, (coords.), Democratización, rendición de cuentas y sociedad civil, participación ciudadana y control social (pp. 245-264). México: CIESAS-Porrúa.

Przeworski, A. (1997). Una defensa de la concepción minimalista de la democracia. Revista Mexicana de Sociología, 59 (3), pp. 3-36.

Reveles, F. (2011). Los estudios sobre los Congresos locales en México.

Estudios Políticos (23), pp. 11-30.

Schedler, A. (2008). ¿Qué es la rendición de cuentas? México: INAI.

Shugart M. y Mainwaring, S. (2002). Presidencialismo y democracia en América latina: revisión de los términos del debate. En S. Mainwaring y M. Shugart (comp.), Presidencialismo y democracia y América Latina (pp. 19-64). Buenos Aires: Paidós.

SEGOB. Secretaría de Gobernación (10 de febrero de 2014).

Decreto por el que se reforman, adicionan y derogan diversas disposiciones de la Constitución Política de los Estados Unidos Mexicanos, en materia política-electoral. Diario Oficial de la Federación. Recuperado de http://www.dof.gob.mx/nota_detalle. php? codigo $=5332025 \&$ fecha $=10 / 02 / 2014$.

Tahar, M. (2012). Crisis de la representación política y democratización en México: de la generalidad a la especificidad del caso. Desafios, 24 (1), pp. 15-36.

TEPJF. Sala Superior del Tribunal Electoral del Poder Judicial de la 
Federación (22 de marzo de 2018). Sentencia del juicio SUPJDC-35/2018 y acumulado. Recuperado de http://www.te.gob.mx/ Informacion_juridiccional/sesion_publica/ejecutoria/sentencias/ SUP-JDC-0035-2018.pdf

Tovar, J. (2010). Condicionantes políticos que impiden la reelección de legisladores en México. Convergencia, Revista de Ciencias Sociales, (53), pp. 87-206.

Ugalde, L. (2002). Rendición de cuentas y Democracia. El caso México. México: Instituto Federal Electoral.

Ugalde, L. y Rivera, G. (2014). La reelección en México: antecedentes y retos de la reforma electoral de 2013. Revista Mexicana de Derecho Electoral, (6), pp. 189-210.

Cómo citar este artículo: Galán, R. (2019). La reelección y el espejismo de la rendición de cuentas en México. Derecho Global. Estudios sobre Derecho y Justicia, 4(11), pp. 91-115. DOI: 10.32870/dgedj.v0i11.220 
